\title{
Periodic Behaviors
}

\section{$11,46-10$ \\ $18+2045$ \\ P.20}

in the Observed Vertical Column Abundances

of Atmospheric Hydroxyl

NSF ATM 86-07193

NASA NAGW-989

January 23, 1989

by

Elizabeth Beaver Burnett

Clyde R. Burnett

Kenneth R. Minschwaner

(NASA-CR-184667) PERICDIC EEEAVIORS IN THE CESEETED VERTICAI CCIUED AEUAI IACES CF ATECSEEEIC BYLECXYL EROGIESS EEFCIT (Florida Atlartic Urive) 20 ,

$\operatorname{CSCL}$ 04A 


\section{Introduction}

The data base for the vertical column abundance of atmospheric hyroxyl (OH) for Fritz Peak Observatory, Colorado $\left(40^{\circ} \mathrm{N}, 105^{\circ} \mathrm{W}\right)$, now extends from 1976 through 1988 and is composed of 8849 independent data sets, averaging about $15 \%$ uncertainty and 20 minute time resolution each. The dominant solar zenith angle $(x)$ dependence of the $\mathrm{OH}$ abundance is characterized by an empirical curve, $N(88)$, which has been updated from $N(82)$ [Burnett, et $a 1,1988$ ] to Include all valid data from 1980 through 1988. The $\chi$-dependence of the $\mathrm{OH}$ abundance has been, to a first order, removed from the data base by a normalization procedure in which each data point is divided by the $N(88, A M)$ value for the corresponding solar zenith angle. The resulting normalized $\mathrm{OH}$ values may then examined for other systematic effects, particularly for periodic variations.

Observations have also been made at Boca Raton, Florida $\left(26^{\circ} \mathrm{N}, 80^{\circ} \mathrm{W}\right)$ and at Truk, Federated States of Micronesia $\left(7^{\circ} \mathrm{N}, 152^{\circ} \mathrm{E}\right)$. These data bases are much less extensive and, as such, are less amenable to analysis for periodic behaviors. Some comparisons with the Colorado data may be made, however. Characterization of the Fritz Peak Data Base through 1988

The Fritz Peak data base for 1980-1988 is shown in Figure 1 where the vertical OH abundances are plotted against the secant of the solar zenith angle $(\sec \chi)$. The empirical $\chi$-dependence, $N(88)$, determined by a polynomial least-squares fit, is also shown. Earlier data, 1977-1979, have a quantitatively different $x$-dependence, particularly at high sun. The differences in the two time periods are discussed in Burnett, et al [1988]. 
The monthly averages of the normalized $\mathrm{OH}$ abundances through 1988 are shown in Figure 2. The $O H$ values gradually increase during the 1977-80 period; from 1980-1988, the average abundance for any year differs from the overal1 average by $3 \%$ at most. (Excluding the 4 summer months in 1982 affected by the E1 Chichon event - see Burnett and Burnett [1984].) The annual variation, maximizing in winter, described for the 1977-1983 data [Burnett and Burnett, 1984] persists through 1988. A summertime sub-maximum is also seen to be a regular feature of the normalized oH abundances. Its magnitude is about $10 \%$. The unusually high summer values in 1982 may be described as a combination of this sub-maximum and the OH increase, about $9 \%$, which occurred during the passage of the EL Chichon cloud.

Examination of this extended data base shows that the winter-time normalized $\mathrm{OH}$ abundance peaks are amplitude-modulated with a maximum in 1980. The amplitudes decrease to a minimum in 1985, and increase through 1988. The summer sub-maximum is similarly modulated. These modulations are in phase with solar activity as described by sunspot cycles 21-22 and shown in Figure 3 .

In order to examine these periodic features in more detail, the long-term behavior of the $\mathrm{OH}$ abundance is removed from the normalized data base. The dashed line in Figure 2, which represents the abundance increase through 1 ate 1979 and the average $P M$ abundance bias through 1988, is subtracted from the data. The El Chichon enhancement is also removed. The resulting set of residual normalized $O H$ abundances is shown in Figure 4 . The basic annual variation is a sinusoid of $22 \%$ amplitude maximizing in January and which is 
modulated by the solid lines in Figure 3 . The superimposed summer submaximum, which is also modulated in phase with the current solar cycle, is a squared sinusoid maximizing in July and extending through May and August. Its maximum amplitude is $19 \%$ above the corresponding minimum in the annual curve. The rms variation of the $O H$ residuals about the composite curve shown in Figure 4 is $50 \%$ less than the rms variation of the $\mathrm{OH}$ abundances about the dashed line in Figure 2. This corresponds to a correlation coefficient between the data and the Figure 4 curve which is significant at the $99 \%$ level. The data in Figure 4 have also been Fourier-analyzed. The resulting power spectrum is shown in Figure 5. The annual and semi-annual features are prominent. A small biennial component not evident in the data base also appears, but not at a significant level. There are no other significant periodicities.

The seasonal behavior of the AM-PM asymmetry in $\mathrm{OH}$ has been reported earlier [Burnett and Burnett, 1984; Burnett, et al, 1988]. The nature of the asymmetry is illustrated in Figure 6 where the average values of oH abundance for spring and fall for 1980-1988 are plotted as a function of solar zenith angle. Figure 7 shows the covariation of the oH diurnal asymetry with total ozone for 1977-1988. It is seen that the amplitudes of both quantities remain relatively constant through 1983 and then decrease to a minimum in 1984-1986 and subsequently increase in 1987-1988. This modulation is similar in both relative amplitude and phase to the modulation of the annual cycle in the normalized OH abundances. 
Burnet, et a1: NSF ATM 86-07193

NASA NAGA-989

\section{Other OH Measurements}

Observations have been reported from Florida for 1980-1986, but the data base has several long gaps so that analysis for periodicities is inconclusive. However, the even-year winters of 1980,1984 , and 1986 (there was no data for 1982) show excursions which decrease in amplitude at approximately the same rate as the Colorado winter amplitudes for the same period. (See Burnett, et al [1988], Figure 3b.)

The observations begun at Truk, FSM, in January of 1987 are to be continued through early 1989 [Minschwaner, et al, 1987]. While variations of the order of $50 \%$ have been observed during 1987-1988, the periodic nature of these variations, if any, is as yet unclear.

\section{Discussion}

\section{General Remarks}

The normalized abundances shown in Figure 2 are not entirely free from seasonal bias. For example, observations for $\sec \times$ near 1 (overhead sun) occur on $1 y$ in the summer; so the summertime normalized abundances may show a diminished departure from the annual average. Similarly, atmospheric observing conditions tend to introduce a seasonal bias at large zenith angles. Nevertheless, we find that the variations described by the curve in Figure 4 do not change significantly when a restricted data base, including only zenith angles for which all seasons are represented, is analyzed.

The calculation of $\mathrm{OH}$ abundances from the absorption data assumes an effective temperature of $250^{\circ} \mathrm{K}$ for the entire column. A small seasonal error resulting in the underestimation of the $\mathrm{OH}$ abundance in winter is thus 
introduced. A $15^{\circ} \mathrm{K}$ difference between effective sumer and winter temperature corresponds to a seasonal error of about $3 \%$ amplitude.

Since these are column measurements and are thus insensitive to altitude, the observed $\mathrm{OH}$ behaviors might be due to variations in tropospheric $\mathrm{OH}$. The tropospheric contribution to the $\mathrm{OH}$ column should vary with seasonal differences in solar zenith angle, water vapor, etc. The effect of the expected high-sun increase in tropospheric $\mathrm{OH}$ in summer will be minimized by our normalization procedure. It is also not clear how the tropospheric column would contribute an annual winter maximum, since tropospheric $O H$ is expected to maximize in the summer [G.H. Mount, personal communication, 1988].

In any case, the seasonal difference attributable to tropospheric oH must be less than the average tropospheric $\mathrm{OH}$ column abundance which is estimated to be about $1 \times 10^{12} / \mathrm{cm}^{2}$ [WMO, 1985], or about $1-2 \%$ of the total observed $\mathrm{OH}$ column. Recent measurements by Platt, et al [1988], give an average mid-day, summer, mid-latitude concentration of $6 \times 10^{6} / \mathrm{cm}^{3}$. If a constant vertical distribution is assumed, this corresponds to a tropospheric $\mathrm{OH}$ column of about $3 \times 10^{12} / \mathrm{cm}^{2}$ or $3 \%$ of the observed summer mid-day oH column abundance.

The dominant role of solar UV flux in the photochemistry of $O H$ is evident in the empirical dependence on sec as shown in Figure 1. Much of the diurnal and seasonal change in the $\mathrm{OH}$ column abundances may be characterized by this single variable. The amplitude of the annual variability in $\mathrm{OH}$ abundances due to changes in solar flux because of the eccentricity of the earth's orbit has been calculated and is about $2 \%$ with a winter maximum [Burnett, 1986]. This gives a combined contribution from annual solar flux and temperature variability of about $5 \%$ amplitude. 
The direct effect of solar UV variability on $\mathrm{OH}$ abundance during a solar cycle has also been examined [Burnett \& Burnett, 1982]. If changes in solar UV flux were the only factor involved, $\mathrm{OH}$ column abundances would be expected to increase modestly between solar minimum and solar maximum. OH abundances were observed to increase by $50 \%$ coincident with the approach to solar maximum during 1977-1980, whereas subsequent $\mathrm{OH}$ abundance levels have remained essentially constant through the declining phase of the past solar cycle (1980-1986) and the initial increasing phase of the current cycle (1986-1988). In contrast to the long-term $\mathrm{OH}$ abundance behavior, observed $\mathrm{OH}$ periodicities show a clear amplitude modulation which is in phase with recent solar activity (see Figures 3 and 4 ). Since a direct photochemical response to UV flux changes during the solar cycle does not adequately describe the observed $\mathrm{OH}$ behaviors, the possible role of transport must be considered.

\section{Transport and $\mathrm{OH}$ Variation}

The direct transport of odd-hydrogen radicals would not be expected to give rise to the observed periodicities because of the very short chemical lifetimes of these species, on the order of minutes in the stratosphere and a few hours in the mesosphere [Shimazaki, 1985]. Long term transport-related changes in source or sink species would give rise to equivalent changes in average odd-hydrogen levels which, since 1980 at least, have not been observed. Hence, those transport mechanisms which may give rise to periodicities in either the source and sink species for odd-hydrogen or in their spatial gradients should be considered as possible factors influencing the observed $\mathrm{OH}$ behavior. 
There are annual cycles of 1) middle atmospheric zonal winds with winter westerlies and summer easterlies and 2) mesospheric cross-equatorial circulation from the summer hemisphere to the winter hemisphere [Andrews, et al, 1987]. A tropical quasi-biennial oscillation (QBO) in stratospheric winds, primarily within 20 degrees of the equator, but with some effects at higher latitudes, is well-established [Reed, 1964; Gray and Pyle, 1988]. A semi-annual oscillation (SAO) in zonal winds also occurs. The SAO has maximum amplitude at the solstices at the stratopause and a maximum amplitude at the equinoxes at the mesopause. The SAO has minimum amplitude at $40^{\circ}$ latitude, about $50 \%$ of its tropical value, and shows little latitudinal phase shift [Andrews, et a1, 1987].

Both the $\mathrm{QBO}$ and $\mathrm{SAO}$ have been tentatively correlated with solar activity. Labitzke [1987] has reported a covariation of middle atmospheric temperatures with solar activity when the temperature data base is partitioned according to the phase of the tropical QBO. An amplitude modulation of about $50 \%$ in the semi-annual zonal winds in phase with solar activity has been reported by Nastrom and Belmont [1980]. That study failed to detect a similar modulation of the annual winds, however. No physical mechanism has yet been identified for either of the above apparent correlations with solar activity. The QBO, annual, and SAO variations in middle atmospheric transport have we11-documented effects on the total abundance and vertical distribution of ozone, especially in the stratosphere where ozone is a reliable dynamic tracer (see, for example, Wilcox, et a1 [1977] and Andrews, et al [1987]). The effect of transport on the distribution of middle-atmospheric water vapor is 
Burnett, et al: NSF ATM 86-07193

NASA NAGA-989

$-8-$

less we11-known due to the difficulties involved in obtaining frequent and reliable observations. Transport effects for most minor constituents in the mesosphere are complicated by short photochemical lifetimes. The transport of odd- hydrogen free radicals should not be involved at any altitude since their chemical lifetimes are always short compared to dynamic lifetimes.

The curve shown in Figure 4 involves a sinusoidal annual cycle added to a summer sub-maximum which is represented by a squared sinusoid. This suggests that separate mechanisms, possibly at different altitudes, are responsible for the net seasonal behavior of $\mathrm{OH}$. It may also be noted that the periodic behavior of $\mathrm{OH}$ in 1977-80 has been assumed to be independent of the high-sun enhanced abundance increase observed during that period. Both periodicities contain a modulation which is proportional to solar activity as measured by the sunspot number index. The AM-PM asymetry (Figure 7) and the Florida abundances also show modulations which are similar in relative amplitude and in phase to those described above. These effects could imply a general modulation of atmospheric circulation, perhaps due to solar activity.

On the other hand, the data shown in Figure 4 could be represented, but not as we11, by a constant 12-month period sinusoid added to a solar activity-modulated 6 -month period sinusoid. This situation would be consistent with other observations which find solar activity correlated with the SAO but not with the annual circulation [Nastrom and Belmont, 1980]. The results of the Fourier-analysis shown in Figure 3 are not inconsistent with either of the above possibilities. In the absence of a firm theoretical framework, any number of possible combinations of periodic and long-term variation could be invoked which would "fit" the observed OH behavior. 
Burnett, et a1: NSF ATM 86-07193

\section{Summary}

We have identified clear periodicities in the seasonal variation of the Colorado $\mathrm{OH}$ data base. The winter maximum and summer sub-maximum are both modulated in phase with the 11-year cycle in solar activity. The Colorado AM-PM asymmetry and the Florida data base show similar modulations. An 11-year modulation of the average Colorado $\mathrm{OH}$ abundances is not, however, observed. We suggest that the observed periodicities and their 11-year modulation result from variations in the transport of the longer-1ived source and sink constituents for the odd-hydrogen free radicals. At this point neither the altitude nor the particular transport process(es) involved can be positively identified, nor can specific physical mechanism which produced the modulations and their correlation with solar activity. 


\section{$\underline{\text { References }}$}

Andrews, D.G., J.R. Holton, and C.B. Leovy, Middle Atmosphere Dynamics, Academic Press (Orlando, FL), 1987.

Burnett, C.R. and E.B. Burnett, "Observational Results on the Vertical Column Abundance of Atmospheric Hydroxyl: Description of Its Seasonal Behavior 1977-1982 and of the E1 Chichon Perturbation", J. Geophys. Res., 89, 9603-11, 1984.

Burnett, C.R. and E.B. Burnett, "Vertical Column Abundance of Atmospheric $\mathrm{OH}$ at Solar Maximum from Fritz Peak, Colorado", Geophys. Res. Lett., $\underline{9}$, $708-11,1982$.

Burnett, C.R., K.R. Minschwaner, and E.B. Burnett, "Vertical Column Abundance Measurements of Atmospheric Hydroxyl from $26^{\circ}, 40^{\circ}$, and $65^{\circ} \mathrm{N}$, J. Geophys. Res., 93, 5241-53, 1988 .

Burnett, E.B., "Quasi-Theoretical Examination of the Principal Results of the Pepsios Ground-based Measurements of the Vertical Column Abundance of Atmospheric Hydroxyl", Report FC-85-547 \#剓, Chemical Manufacturers' Association (Washington, DC), 1986. 
Gray, L.J. and J.A. Pyle, "A Two-dimensional Model of the Ouasi-Biennial Oscillation of Ozone", J. Atmos. Sci., in press, 1988.

Labitzke, K., "Sunspots, the QBO, and the Stratospheric Temperature in the North Polar Region", Geophys. Res. Lett., 14, 535-37, 1987.

Minschwaner, K.R., C.R. Burnett, and E.B. Burnett, "Tropical OH Column Abundance Measurements at Truk, Federated States of Micronesia", Eos Trans. $\mathrm{AGU}, \underline{68}, 1235,1987$.

Nastrom, G.D. and A.D. Belmont, "Apparent Solar Cycle Influence on Long-Period Oscillations in Stratospheric Zonal Wind Speed", Geophys. Res. Lett., $6,457-60,1980$.

National Geophysical Data Center (NGDC), Solar Indices Bulletin, (Boulder, CO), 1988 .

Platt, U., M. Rateike, W. Junkermann, J. Rudolf, and D.H. Ehhalt, "New Tropospheric OH Measurements", J. Geophys. Res., 93, 5159-66, 1988.

Reed, R.J., "A Tentative Model of the 26-month Oscil1ation in Tropica1 Latitudes", Q.J.R. Meteoro1. Soc., 90, 441-66, 1964. 
Burnett, et a1: NSF ATM 86-07193

Shimazaki, Tatsuo, Minor Constituents in the Middle Atmosphere, D. Reide1 (Boston, MA), 1985 .

Wilcox, R.W., G.D. Nastrom, and A.D. Belmont, "Periodic Variations in Total Ozone and of Its Vertical Distribution", J. Appl. Meteorol., 16, $290-98,1977$

World Meteorological Organization (WMO), Atmospheric Ozone: 1985, Report 16, Globa1 Ozone Research and Monitoring Project (Geneva), 1986. 


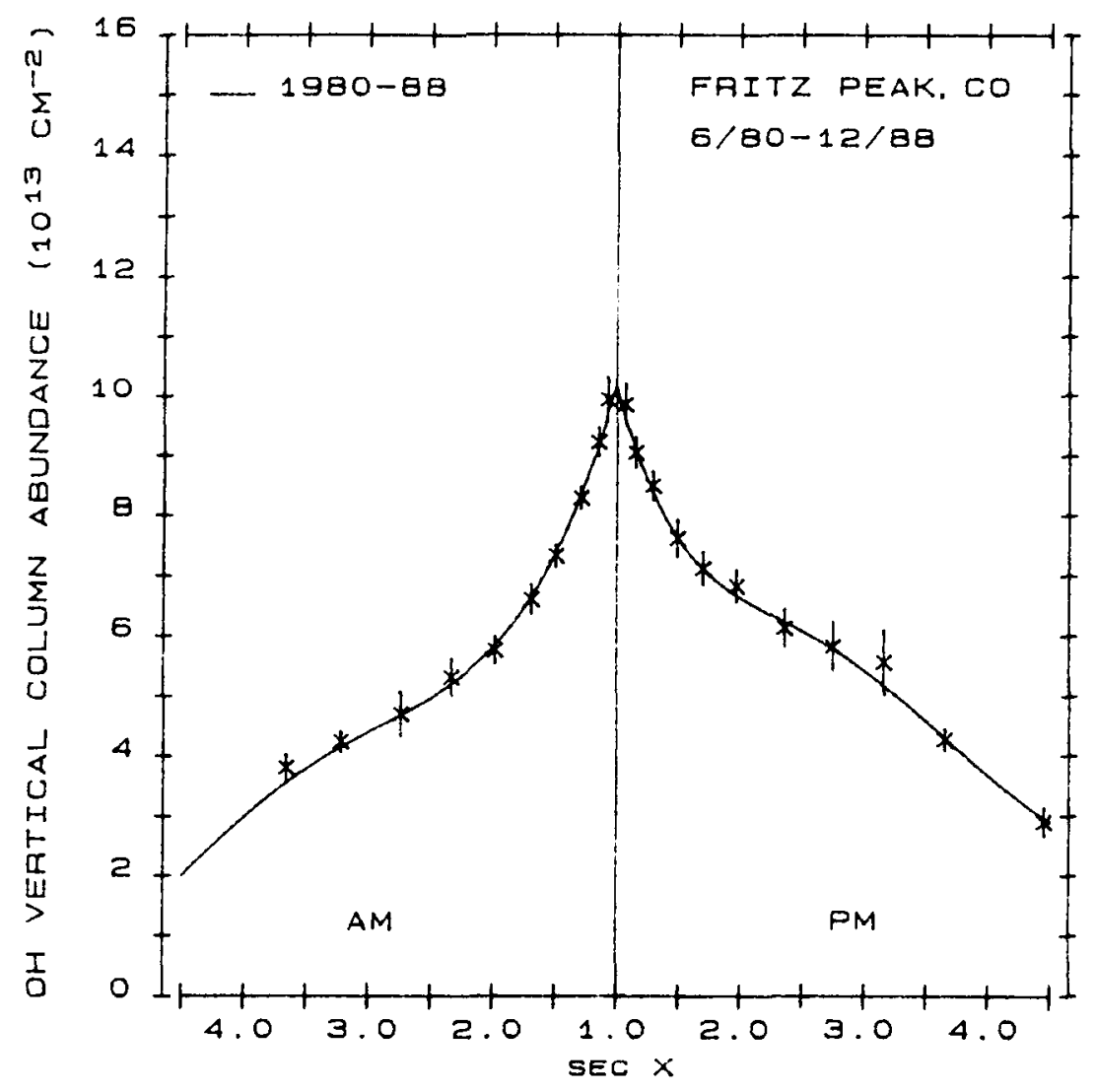

Figure 1 Average solar zenith angle dependence of the vertical column abundance of atmospheric $\mathrm{OH}$ at Fritz Peak, Colorado $\left(40^{\circ} \mathrm{N}, 105^{\circ} \mathrm{W}\right) 1980-1988$. The average oH vertical column abundances, $\mathrm{Nv}$, are calculated from 8849 independent absorption measurements and are displayed as a function of the secant of the solar zenith angle, $x$. The empirical curve shown is a non-linear least squares fit to the data and has a standard error of fit of $0.12 \times 10^{13} / \mathrm{cm}^{2}$. Error bars represent the standard error of the mean, $\sigma / \sqrt{ }$. 


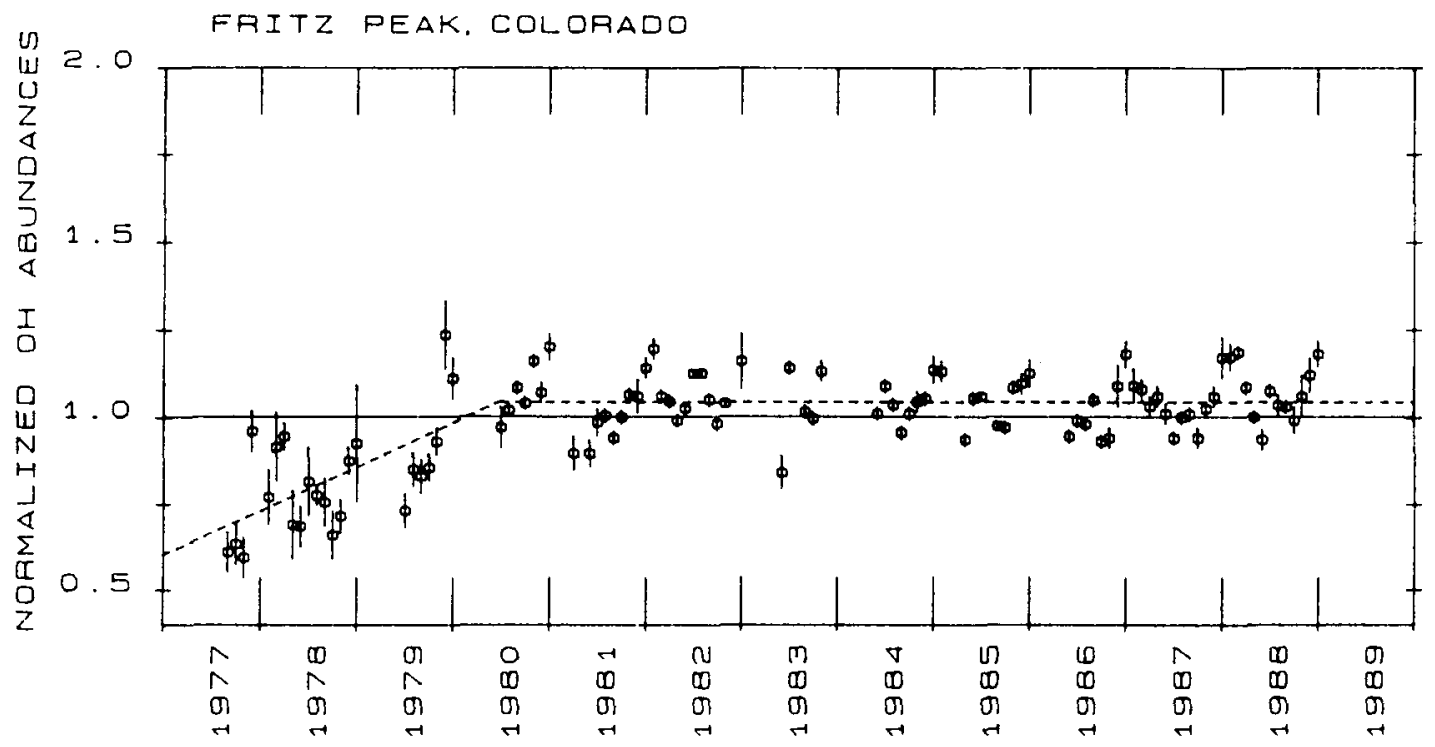

Figure 2 Monthly averages of normalized oH abundances for the period 1977-1988. OH abundances have been normalized by dividing by the $N(88, A M)$ empirical curve from Figure 1 . The dashed line shows the approximately linear abundance increase observed from 1977 through 1979 and the subsequent constant average OH abundance. The horizontal portion of the dotted line is off-set from zero due to the persistant $O H$ abundance bias toward PM values. The rms deviation of normalized $O H$ abundance about the dashed line is 0.085 . 


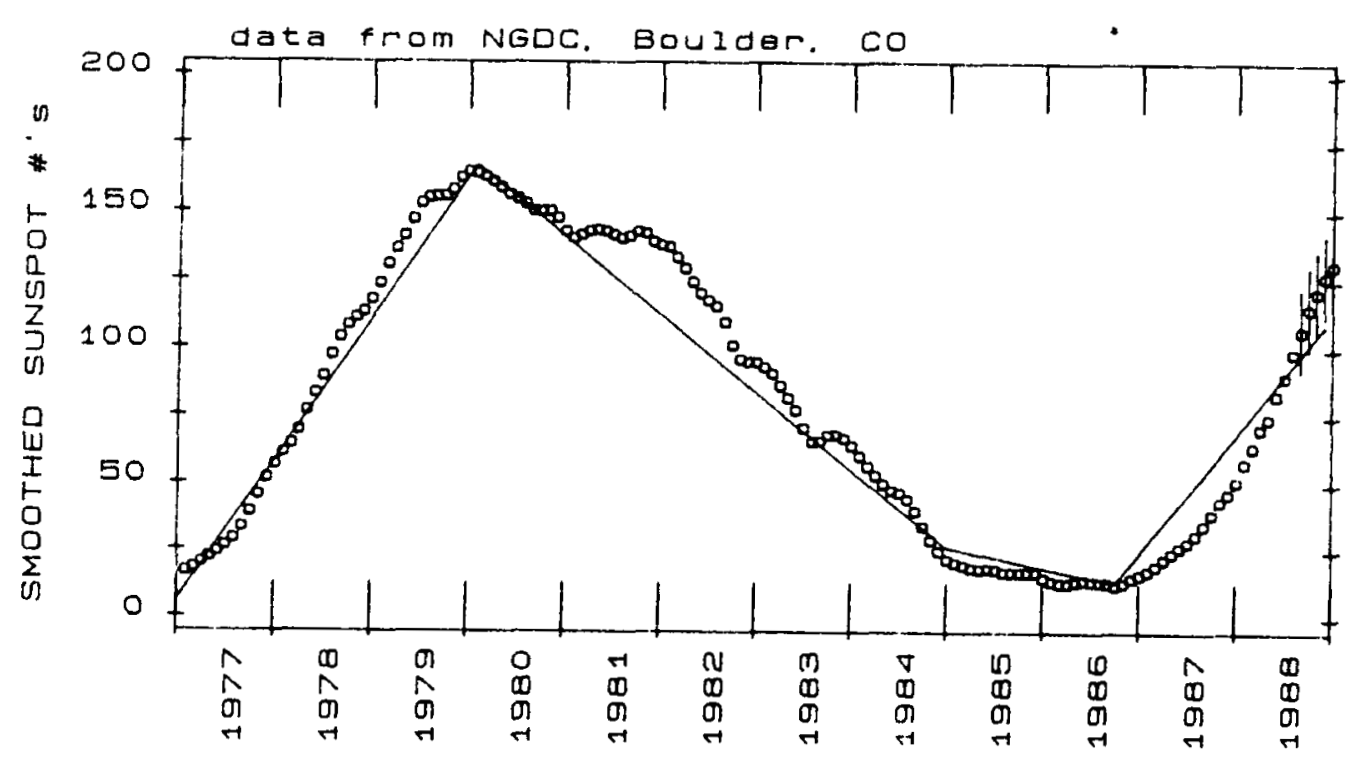

Figure 3 Smoothed sunspot numbers for the 1977-1988 period. The circles represent solar activity as defined by the sunspot number index [NGDC, 1988]. Solar maximum of cycle 21 occurred in December 1979 and the onset of solar cycle 22 occurred in september 1986. The solid lines are proportional to the lines used to modulate the amplitude of the 12-month cycle observed in the normalized oH data base. 


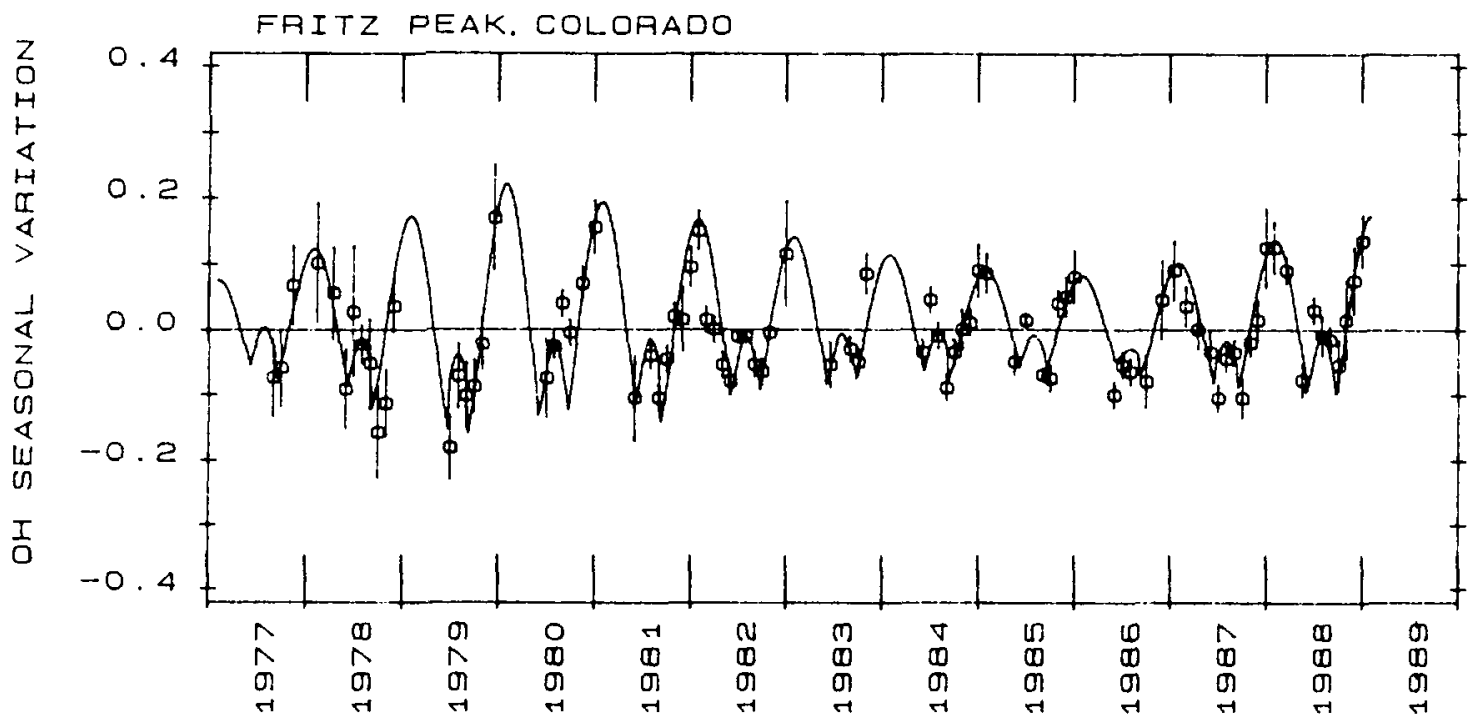

Figure 4 Modulated seasonal variations of normalized oH column abundances at Fritz Peak, $C O$. The circles represent residuals from the normalized $\mathrm{OH}$ abundances when the long-term average $\mathrm{OH}$ behavior (the dashed line shown in Figure 2) is subtracted. The curve represents the sum of a) an annual sinusoid of amplitude 0.22 , maximizing in January and amplitude-modulated proportional to solar activity (solid line in Figure 3); and b) a modulated, squared sinusoid extending from May through August, maximizing in July, and having a maximum amplitude of 0.19 above the corresponding July minimum in the annual curve. The rms deviation of the $\mathrm{OH}$ residuals from the curve shown is 0.041 . The minimum statistically significant rms deviation of a monthly mean for a data base of 8850 observations with an average experimental uncertainty per observation of $15 \%$ is 0.016 . 


\section{ORIGINAL PAGE IS OF. POOR QUALITY}

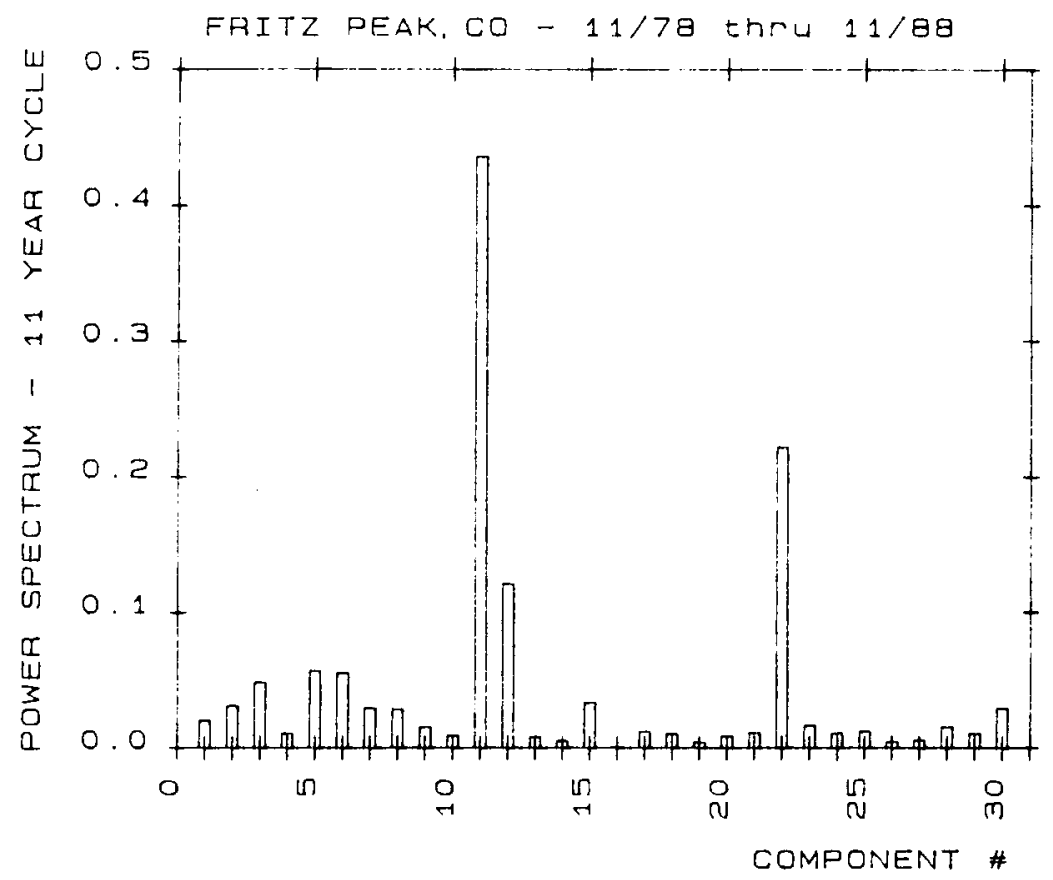

Figure 5 Discrete power spectrum for the normalized OH abundances for 1977-1988. The power spectrum from a full Fourier analysis of the normalized $\mathrm{OH}$ abundances is shown. Components 11,12 , and 22 are significant. Components 11 and 12 have a frequency corresponding to an annual cycle in the data base. The phase of these components is consistent with the observed January maximum. Component 22 is consistent with either a true semi-annual cycle, an annual cycle out of phase with the primary annual periodicity, or an annually-occurring sub-maximum. Its phase shows a July maximum. Components 5 and 6 correspond to a biennial cycle and are of marginal significance; such a periodicity is not apparent in the Colorado data base. 
ORIGINAL PAGE IS

OF POOR QUALITY

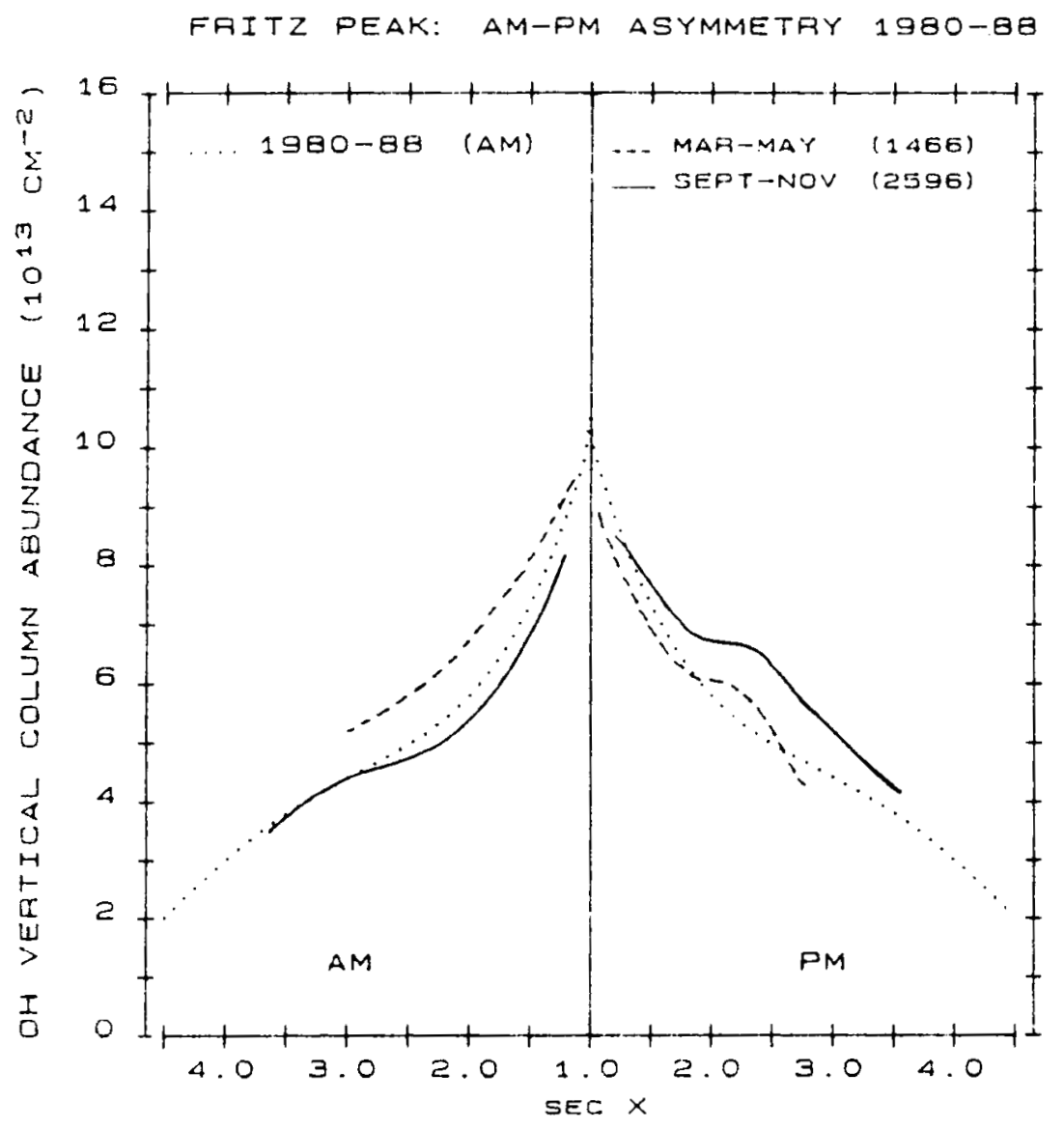

Figure 6 Average spring and fall asymmetry in oH column abundances for 1980-1988. The empirical curve $N(88, A M)$ is shown on both the morning and afternoon side of the graph in order to provide a symmetric reference. The average spring curve (March through May) is obtained from 1466 data sets and is represented by the dashed 1 ines. The average fall curve (September through November) is obtained from 2596 data sets and is represented by the solid lines. The curves are oppositely asymetric with respect to morning and afternoon. The earlier, 1977-1979, $\mathrm{OH}$ data show a similar asymmetry. 


\section{ORIGINAL PAGE IS OF. POOR QUALITY}

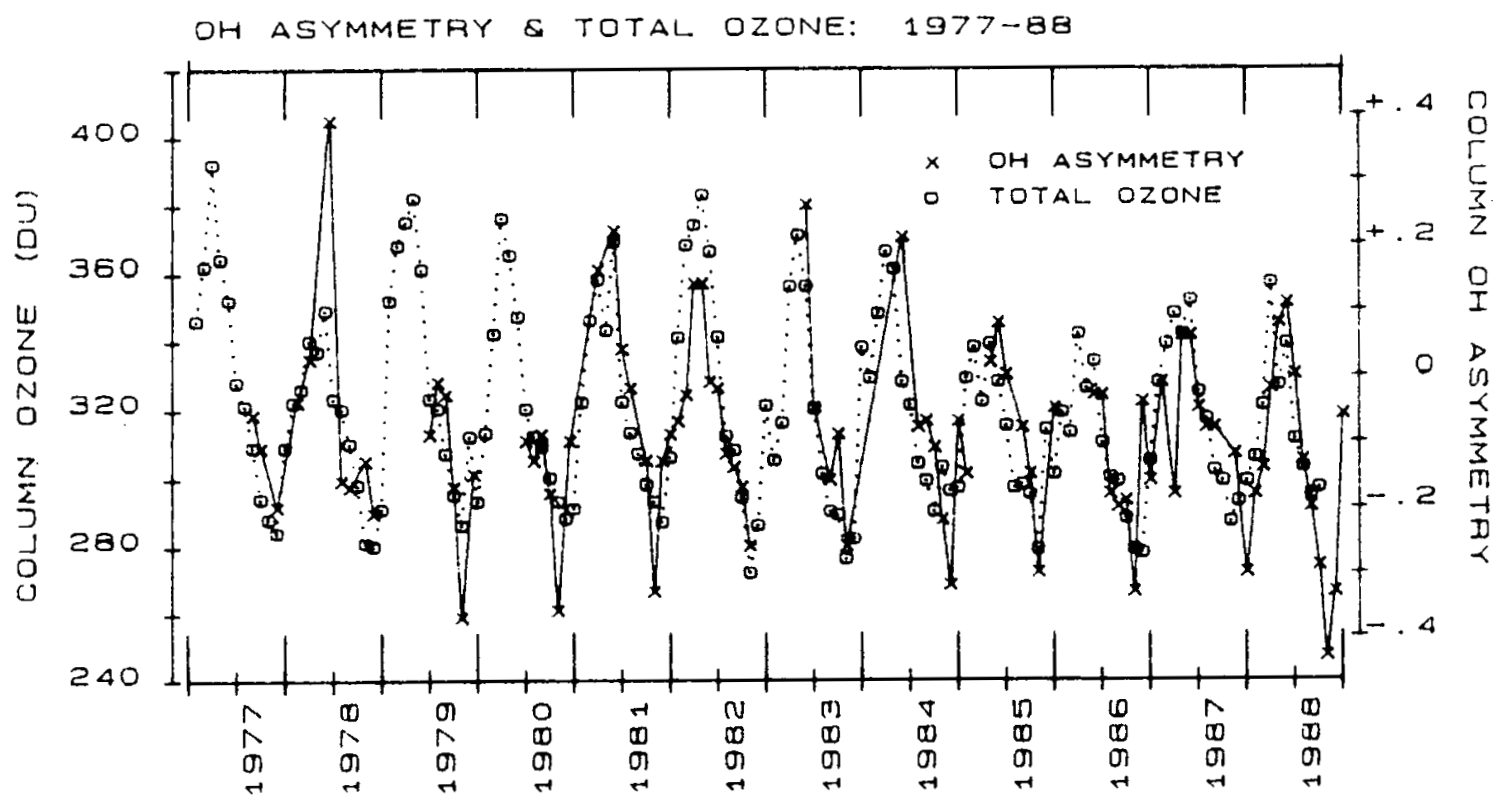

Figure 7 Seasonally varying $\mathrm{OH}$ asymmetry and total ozone abundances for Colorado, 1977-1988. The crosses represent the monthly mean ozone column abundances for Boulder, CO [GMCC data courtesy of R. Grass]. The circles represent the monthly values of the $O H$ asymmetry (see Burnett, et al, 1988 for details). In addition to the annual covariance of the two data sets, each shows an amplitude modulation of approximately $50 \%$ beginning in 1983, minimizing in 1986 , and increasing through 1988 . 